\title{
Comparative Study of Precancerous Lesions of the Uterine Cervix Among Users and Non-Users of Combined Oral Contraceptive Pills in Jos, Nigeria
}

\author{
Yakubu Emmanuel Nyam ${ }^{1}$ Ajen Stephen Anzaku², Innocent Emmanuel ${ }^{3}$, \\ Isikhuemen Ehikoya Maradona ${ }^{4}$, Ekwedigwe Chinedu Kenneth ${ }^{5}$, Daru Patrick Haruna ${ }^{1}$, \\ Ocheke Ngozi Amaka ${ }^{1}$, Ujah Achanya Otobo Innocent ${ }^{1}$ \\ ${ }^{1}$ Department of Obstetrics and Gynaecology, Jos University Teaching Hospital, Jos, Nigeria \\ ${ }^{2}$ Department of Obstetrics and Gynaecology, Bingham University Teaching Hospital, Jos, Nigeria \\ ${ }^{3}$ Department of Histopathology, Jos University Teaching Hospital, Jos, Nigeria \\ ${ }^{4}$ Department of Obstetrics and Gynaecology, University of Benin Teaching Hospital, Benin City, Nigeria \\ ${ }^{5}$ National Obstetric Fistula Centre, Abakaliki, Nigeria \\ Email address: \\ emayaks75@yahoo.com (Y. E. Nyam)
}

\section{To cite this article:}

Yakubu, Emmanuel Nyam, Ajen Stephen Anzaku, Innocent Emmanuel, Isikhuemen Ehikoya Maradona, Ekwedigwe, Chinedu Kenneth, Daru Patrick Haruna, Ocheke Ngozi Amaka, Ujah Achanya Otobo Innocent. Comparative Study of Precancerous Lesions of the Uterine Cervix Among Users and Non-Users of Combined Oral Contraceptive Pills in Jos, Nigeria. International Journal of Clinical Oncology and Cancer Research. Vol. 3, No. 3, 2018, pp. 35-40. doi: 10.11648/j.ijcocr.20180303.14

Received: January 3, 2018; Accepted: August 31, 2018; Published: September 27, 2018

\begin{abstract}
Combined oral contraceptive pills (COCP) use, is link to the development of precancerous cervical lesions. There are variations in reports across studied populations. Our study was a comparative, cross-sectional study. SPSS version 20 (IBM, Armonk, NY, USA) was used for data analysis and P-Value $<0.05$ was considered statistically significant. The Prevalence of precancerous cervical lesions in the Exposed and Control groups were 16.4\% (9/55) and 14.5\% (8/55) respectively ( $\mathrm{P}=$ of 0.79$)$. In the exposed group, four out of the nine women that had abnormal cervical cytology results had high grade squamous intra-epithelial lesions (HGSIL) while only one out of 8 women that had abnormal cytology results in the control group had HGSIL. We found no significant difference in the prevalence of pre-cancerous cervical lesions between users and non-users of COCP. However, women who used COCP had higher cases of HGSIL when compared with the control group. Therefore, we suggest relatively short schedule of cervical cytology screening for this group of women relative to the general population.
\end{abstract}

Keywords: Papanicolaou Smear Test, Combined Oral Contraceptive Pills, Precancerous Cervical Lesions

\section{Introduction}

Although combined oral contraceptive pills have been of great benefit in fertility regulation over the years, reports suggest that there may be increased risk of development of cervical pre-cancerous lesions and cancer of the cervix following the use of combined oral contraceptive pills especially over a long period [1]. A period of between $1-5$ years of using combined oral contraceptive pills for precancerous cervical lesions to occur have been reported [2].
Cervical cancer is the second most common cancer in women worldwide [2]. In Northern Nigeria, cancer of the cervix appears to be the commonest cancer in women while in the southern part of Nigeria, cervical cancer is second to breast cancer [3]. About $60-75 \%$ of women in Sub-Saharan Africa who develop cervical cancer live in rural areas where mortality from the disease is high probably because of lack of awareness of the disease and poor access to quality health care services [3]. It is estimated that about 47.72 million Nigerian women are at risk of cervical cancer [4]. The annual number of cervical cancer cases in Nigeria is 14,089 and the 
annual number of cancer deaths is 8,240 [4]. The prevalence of cervical cancer is low in developed countries because of well-organised screening programmes and good awareness of the disease [4]. Human papillomavirus (HPV) is an established risk factor for cervical cancer and its precursor lesions but it is not sufficient in it itself or by itself because not all women who have HPV infection develop carcinoma of the cervix [5].

The use of combined oral contraceptive pills has been identified as risk factor in the development of cervical carcinogenesis [5]. Combined oral contraceptive pills usage is one of the common methods of contraception in Jos, Nigeria [6]. Globally, more than 300 million women currently use oral hormonal contraceptive pills daily [5]. Hormonal contraceptive pills which contain artificially synthesized versions of the female sex hormones, oestrogen and progesterone, have revolutionized fertility control since when they became available for clinical use over forty years ago [7]. The mechanism by which combined oral contraceptive pills might increase a woman's risk of developing cervical cancer has not been clearly defined. However, several mechanisms have been proposed [8]. The fear and anxiety for cervical cancer following the use of combined oral contraceptives pills can affect the uptake and compliance of this modern method [2].

This study was therefore conducted to determine the prevalence and pattern of precancerous cervical lesions among users and non-users of hormonal contraceptives in our clinical settings.

\section{Materials and Methods}

This study was conducted at the family planning, Gynaecology and Gynae-oncology clinics of Jos University Teaching Hospital (JUTH) and Bingham University Teaching Hospital (BHUTH) all located in Jos, Plateau state, Nigeria. These two hospitals are currently the only two major tertiary teaching health institutions in the state. Jos is the capital city of Plateau state, located in North-central, Nigeria. This was a hospital-based comparative cross-sectional study conducted among women using Combined Oral Contraceptive Pills for at least one year (exposed group) and the non-users of any of hormonal contraceptives (at the time of study) who served as controls. The study period was from July 2015 to December 2016. The exposed and control groups were matched for covariables of precancerous and cancerous lesions of the cervix.

Inclusion criteria were all eligible women who provided informed consent for the study and were currently using combined oral contraceptives pills alone for at least one year (exposure group) and all eligible women who were not using any form of hormonal contraceptive method (control group). However, women who were using any form of hormonal contraceptive apart from combined oral contraceptives, those who had ulcerative cervical lesions and those that declined consent for this study were excluded from the study.

A minimum sample size of approximately 100 was calculated using the formula $\mathrm{n}=\mathrm{Z}^{2} \mathrm{Pq} / \mathrm{d}^{2}$ and prevalence of abnormal cervical cytology of $7.0 \%$ [9]. Adjusting for possible attrition rate of $10 \%$, final sample size of 110 was determined consisting of 55 women each in the exposed and control groups. The women were recruited through convenience sampling technique. A written informed consent was obtained from each of the participants before they were recruited for this study. All Data obtained from the women was recorded in a structured proforma that were earlier administered to all eligible participants by trained female Nurses. The information concerning socio-demographic and bio-demographic factors which included relevant menstrual history, sexual behaviour and reproductive history were obtained from each client and documented. The two groups of women were matched for age in years, Parity, age at first sexual intercourse, number of sexual partners, tobacco smoking status, and HPV-DNA and HIV infection status. The cervical samples were taken using Rovers cervix brush and were transferred into PreservCyt solution for preservation prior to HPV-DNA test. Their HPV DNA infection status was determined from the cervical samples with the aid of automated machine, Cobass 4800 machine, which was designed for amplification and detection of the nucleic acid content of HPV-DNA in cervical samples. The retroviral screening test was done using rapid screening test by the use of Determine strips. The Pap smear samples were taken using Ayre's spatula and analysed using Leica's Microscope and cytology results reported according to Bethesda system of cytological classification.

The data was analysed using the Statistical Package for Social Sciences (SPSS) version 20 (IBM, Armonk, NY, USA). P-value $<0.05$ was considered statistically significant.

Ethical approvals for the study were obtained from the Ethics and Research committee of Jos University Teaching hospital and Human Research and ethics Committee of Bingham University Teaching Hospital, Jos.

\section{Results}

A total of 110 participants were involved in the study. The overall mean age was $32.7 \pm 5.8$ years but $33.02 \pm 6.0$ and $32.5 \pm 5.9$ years were the mean ages of the exposure and control groups respectively. Table 1 depicts the sociodemographic features of the study populations. A total of 76 $(69.1 \%)$ of the study populations were multiparous. The overall mean age at first sexual intercourse was $19.70 \pm 2.8$ years. In the study population, the age at first intercourse was not significantly different $(\mathrm{P}=1.46)$ between the exposed and

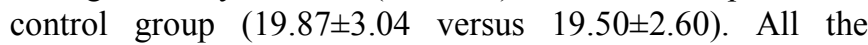
women never used tobacco in any form in their life time. Among the study populations, 19(17.27\%) of them disclosed that they had more than one sexual partner in their life time while $78(70.91 \%)$ subjects admitted having one sexual partner in their life time. Table 2 shows the obstetrics and sexual characteristics of the subjects.

The Prevalence of precancerous cervical lesions in the two studied population were $16.4 \%(n=9)$ for users of combined 
oral contraceptive pills and $14.5 \%(n=8)$ for non-users of combined oral contraceptive pill (Figure 1). Figure 2 shows the pattern of abnormal cervical cytology in the study populations. With respect to high grade squamous intraepithelial lesions (HGSIL), four (40\%) of the women that had abnormal cytology results among users of Combined oral contraceptive pills had HGSIL while one (12.5\%) was found among non-users of combined oral contraceptive pills.
Among women on combined oral contraceptive pill, one $(10 \%)$ of them had inflammatory cells alone in her Pap smear sample, 30\% had ASC-US, $20 \%$ had LGSIL and $40 \%$ had HGSIL. Meanwhile, the pattern of abnormal cervical cytology among non-users of hormonal contraceptive revealed; $50 \%$ had ASCU-S, 37.5\% had LGSIL and 12.5\% had HGSIL. None of them had inflammatory cells in the Pap smear.

Table 1. Socio-demographic characteristics of the study population

\begin{tabular}{|c|c|c|c|c|}
\hline \multirow{2}{*}{ Characteristics } & \multirow{2}{*}{$\begin{array}{l}\text { Exposed } \\
\text { N }(\%) \\
\end{array}$} & \multirow{2}{*}{$\begin{array}{l}\text { Control } \\
\mathbf{N}(\%) \\
\end{array}$} & \multirow{2}{*}{$\mathrm{X}^{2}$ test } & \multirow{2}{*}{ P-Value } \\
\hline & & & & \\
\hline \multicolumn{5}{|l|}{ AGE } \\
\hline Mean SD & $33.02 \pm 6.0$ & $32.5 \pm 5.9$ & 0.50 & \\
\hline$<=25$ & $1(1.8 \%)$ & $5(9.1 \%)$ & 3.29 & 0.19 \\
\hline $26-35$ & $39(70.9 \%)$ & $33(60.0 \%)$ & & \\
\hline $36+$ & $15(27.3 \%)$ & $17(30.9)$ & & \\
\hline Total & $55(100.0 \%)$ & $55(100.0 \%)$ & & \\
\hline \multicolumn{5}{|l|}{ Religion } \\
\hline Christianity & $38(69.1 \%)$ & $33(60.0 \%)$ & 0.99 & 0.32 \\
\hline Islam & $17(30.9 \%)$ & $22(40.0 \%)$ & & \\
\hline Total & $55(100.0 \%)$ & $55(100.0 \%)$ & & \\
\hline \multicolumn{5}{|l|}{ Educational Status } \\
\hline None & $0(0.0 \%)$ & $2(3.6 \%)$ & 4.29 & 0.37 \\
\hline Informal & $2(3.6 \%)$ & $5(9.1 \%)$ & & \\
\hline Secondary & $15(27.3 \%)$ & $10(18.25 \%)$ & & \\
\hline Tertiary & $30(54.5 \%)$ & $30(54.5 \%)$ & & \\
\hline Total & $55(100.0 \%)$ & $55(100.0 \%)$ & & \\
\hline \multicolumn{5}{|l|}{ Occupation } \\
\hline Public Servant & $15(27.3 \%)$ & $20(36.4 \%)$ & 3.34 & 0.50 \\
\hline Business & $20(36.4 \%)$ & $12(21.8 \%)$ & & \\
\hline Farming & $1(1.8 \%)$ & $1(1.8 \%)$ & & \\
\hline Housewife & $13(23.6 \%)$ & $17(30.9 \%)$ & & \\
\hline Unemployed & $6(10.9 \%)$ & $5(9.1 \%)$ & & \\
\hline Total & $55(100.0 \%)$ & $55(100.0 \%)$ & & \\
\hline \multicolumn{5}{|l|}{ Marital Status } \\
\hline Single & $0(0.0 \%)$ & $2(3.6 \%)$ & 6.00 & 0.11 \\
\hline Married & $52(94.5 \%)$ & $44(80.0 \%)$ & & \\
\hline Divorced & $2(3.6 \%)$ & $4(7.3 \%)$ & & \\
\hline Widowed & $1(1.8 \%)$ & $5(9.1 \%)$ & & \\
\hline
\end{tabular}

Table 2. Bio-demographic characteristics of the study population

\begin{tabular}{|c|c|c|c|c|}
\hline \multirow{2}{*}{ Characteristics } & \multirow{2}{*}{$\begin{array}{l}\text { Exposed } \\
\text { n (\%) }\end{array}$} & \multirow{2}{*}{$\begin{array}{l}\text { Control } \\
\text { n (\%) }\end{array}$} & \multirow{2}{*}{$\mathrm{Chi}^{2}$ Test } & \multirow{2}{*}{ P-Value } \\
\hline & & & & \\
\hline All subjects & $55(50.0)$ & $55(50.0)$ & & \\
\hline \multicolumn{5}{|l|}{ Parity } \\
\hline Prim parity (1) & $5(9.1 \%)$ & $5(9.1 \%)$ & $\mathrm{X}^{2}=0.1$ & 1.00 \\
\hline Multi Parity (2-4) & $38(69.1 \%)$ & $38(69.1 \%)$ & & \\
\hline Grand-Multi Parity (5 and above) & $12(21.8 \%)$ & $12(21.8 \%)$ & & \\
\hline Total & $55(100.0 \%)$ & $55(100.0 \%)$ & & \\
\hline Age at first sexual intercourse & $19.87 \pm 3.04$ & $19.5 \pm 2.60$ & -0.73 & 1.46 \\
\hline \multicolumn{5}{|l|}{ Smoking Habit } \\
\hline Yes & $0(0.0 \%)$ & $1(1.8 \%)$ & $X^{2}=1.0$ & 0.32 \\
\hline No & $55(100.0 \%)$ & $54(98.2 \%)$ & & \\
\hline Total & $55(100.0 \%)$ & $55(100.0 \%)$ & & \\
\hline \multicolumn{5}{|l|}{ Life time number of Sexual Partners } \\
\hline$>1$ Partners & $9(47.4 \%)$ & $10(52.6 \%)$ & $\mathrm{X}^{2}=0.26$ & 0.61 \\
\hline 1 Partner & $42(53.8 \%)$ & $36(46.2 \%)$ & & \\
\hline Total & $51(52.6 \%)$ & $46(47.4 \%)$ & & \\
\hline
\end{tabular}




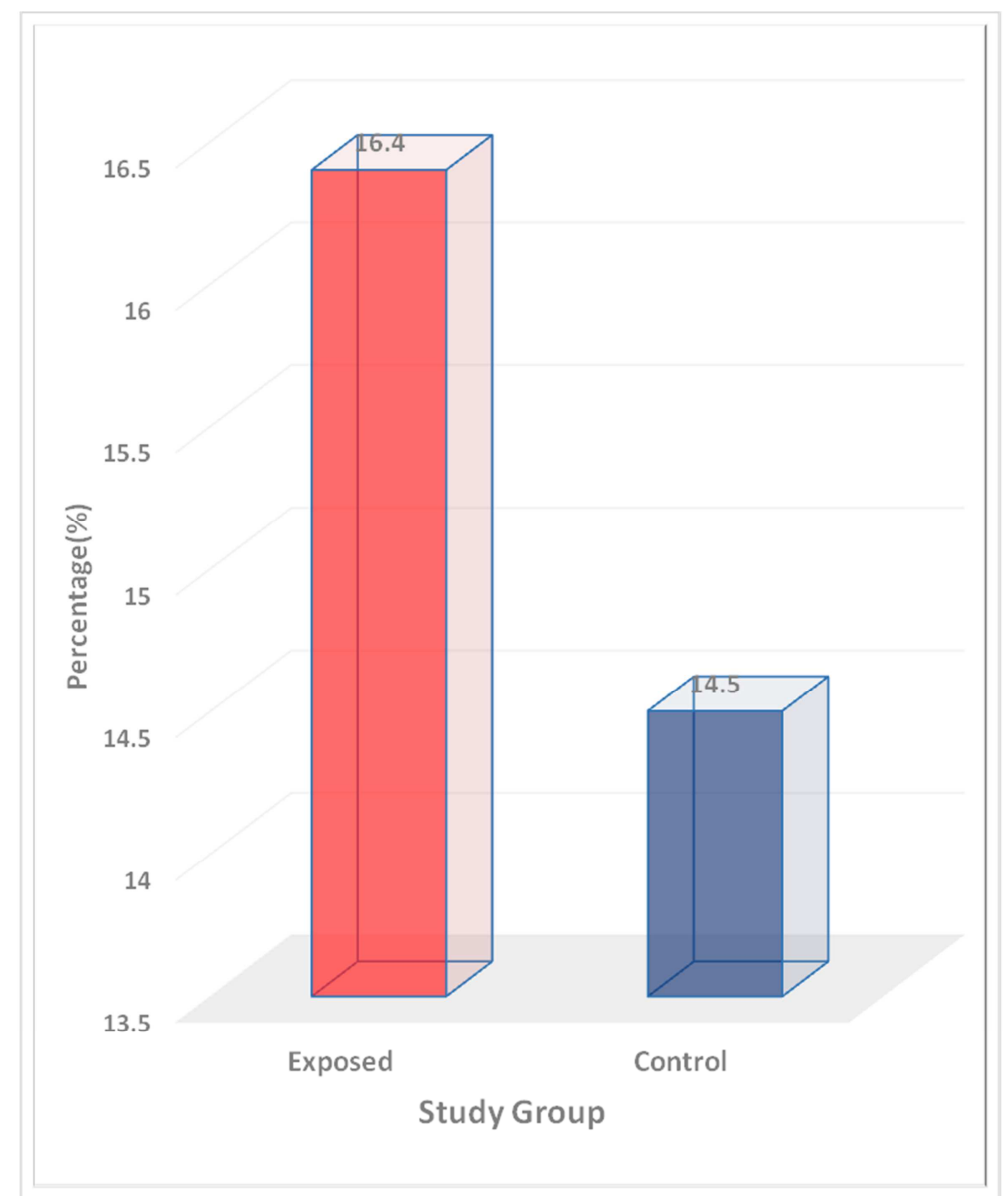

Figure 1. Prevalence of Precancerous cervical lesions among the study populations

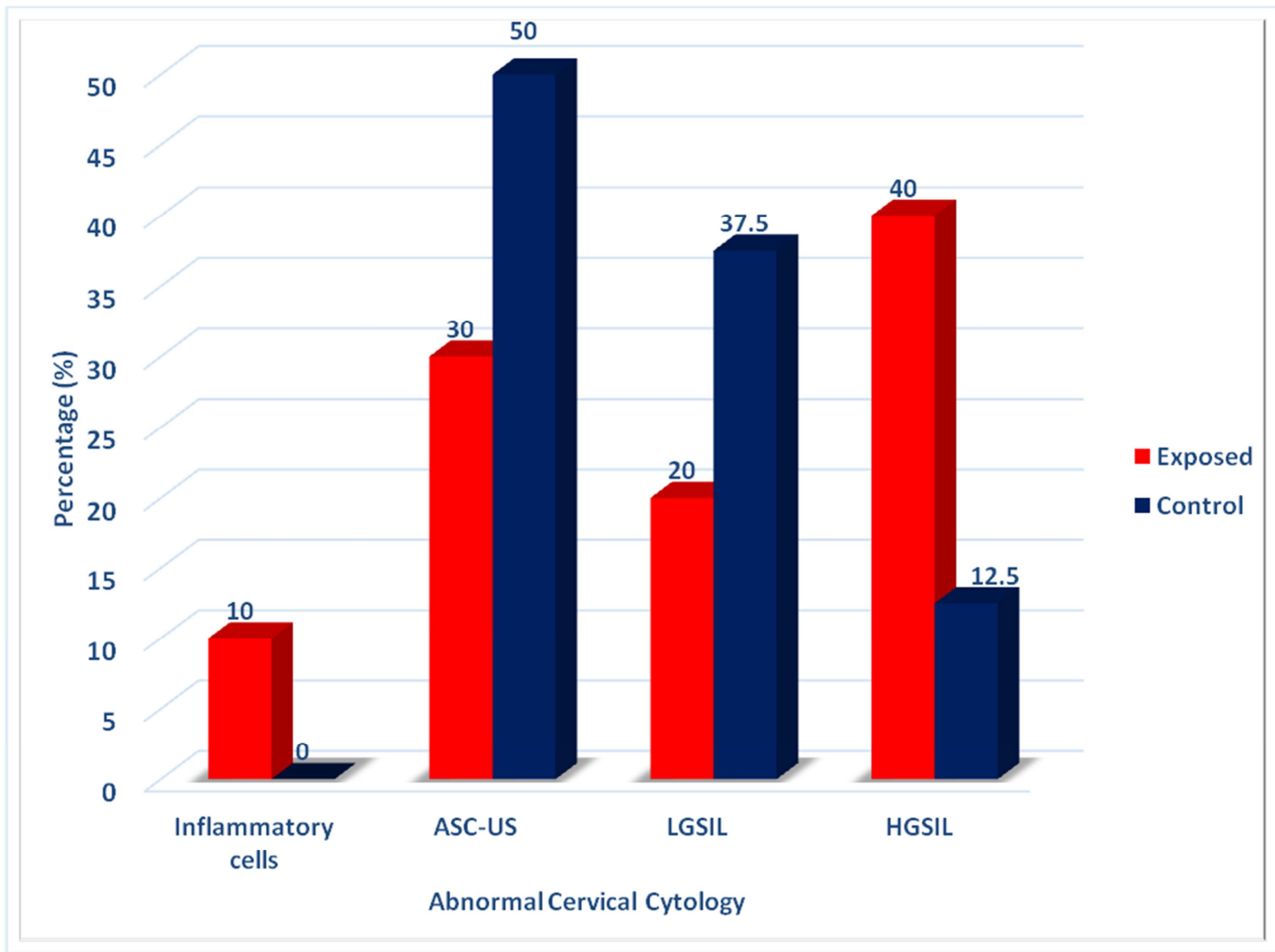

Figure 2. Pattern of abnormal cervical cytology among the study populations 


\section{Discussion}

The findings from this study have important implications for clinical practice and future research work. This study revealed that, the prevalence of precancerous cervical lesions among users of combined oral contraceptive pills was $16.4 \%$ compared the $14.5 \%$ among non-users of hormonal contraceptive. However there was no statistical significant difference between the cases and the controls. This is perhaps, a reflection of the persistent burden of pre-cancerous lesions of the cervix in the developing countries. There is therefore, the need to scale up efforts in a well-organized and efficient system to ensure cervical cancer screening, prompt treatment of precancerous cervical lesions to prevent possible progression to cervical malignancy. In addition, effective follow-up measures should be implemented to also prevent possible progression to invasive cervical cancers. The prevalence rate, from this study is in line with the prevalence rates of 6.8 to $16.1 \%$ of abnormal cervical epithelial changes reported from northern Nigeria [9]. The prevalence rate of precancerous lesions of the cervix in this study is also similar to the rates of $16.31 \%$ and $16.20 \%$ reported by Ayodele Omotoso et al. and Obaseki DE et al in the Southern part of Nigeria [10,11]. Other researchers who also reported similar prevalence rates compared to this study include: Muhammad Hauwa Inna in a published Thesis online who reported 13.9\% [13] as well as the report from Mosuro A.O [13] et al. who also reported $13.9 \%$ as the prevalence rate of precancerous cervical lesions.

However, the prevalence rate found in this study is lower than the $22.6 \%$ prevalence rate of abnormal cervical cytology reported by Duru C.B et al. [14] from South-east Nigeria, and $39.7 \%$ prevalence rate previously reported by Daru PH et al. [15] from Jos, North-central Nigeria. The figure reported by Daru P.H et al was far higher than that of our study and this disparity may be attributable to differences in methodology in reporting cervical cytology. The higher prevalence rate reported by Duru C.B et al. [14] could be explained by the older population reported in their study which had a mean age of $46 \pm 13$ years compared to the relatively younger study population with a mean age of $32.7 \pm 5.8$ years in our study. Duru $\mathrm{CB}$ et al. included women who had abnormal vaginal bleeding which could have contributed to the relatively higher prevalence rate reported in his study. In our study, those group women were excluded which may have been responsible for the difference in the prevalence rate of precancerous lesions of the cervix.

Conversely, the prevalence rate found in our study is higher than the $7.8 \%$ as reported by Bukar M. et al. [16] from Maiduguri, North-east Nigeria. This difference may be attributable to different criteria used by Bukar $M$ et al. [16] in reporting and categorization of Pap smear results, in which 'CIN system classification' was adopted instead of the 'Bethesda system of classification' for Pap smear adopted in this study. Other published studies whose prevalence rates were lower than the one reported in our study include that by
Avidime et al. [17], Banik U et al. [18] and Ajah L.O and coworkers [19].

This study again revealed no significant difference in the two prevalence rates of precancerous cervical lesions among users of combined oral contraceptives and non-users of combined oral hormonal contraceptives. This implies that the burden of precancerous cervical lesions may not be wholly linked to hormonal milieu involving Oestrogens and Progestogens.

Based on this study, the pattern of precancerous cervical lesion revealed that nine women out of the fifty five women in the exposed group had abnormal cervical cytology screening test; out of these ten affected women, four had high grade squamous intraepithelial lesions. While in the control group, eight women had abnormal cervical cytology test in the control group, from these eight affected women in the control group, one woman had high grade squamous intraepithelial lesion. However, we found higher number of cases of HGSIL among users of COCPs compared to nonusers of hormonal contraceptives. This may suggest that women who use combined oral contraceptive pills for at least one year are likely to develop higher grades of precancerous lesions of the cervix (HGSIL) which is known to have the highest propensity to progress to cervical cancer compared to other grades of precancerous lesion of the cervix. Hence, this finding underscores the need for awareness for users of COCPs and need for strategies among contraceptive/family planning healthcare providers and stakeholders to formulate policy and guidelines for prolong users of COCPs regarding their probable increased chance of developing high grade cervical lesions especially among those that use it for at least one year. Based on this comparative study on the pattern of precancerous cervical lesion, we therefore advocate close monitoring of women on combined oral contraceptive pills for one year or more so as to enable timely detection and hence early and prompt treatment of cervical lesions.

\section{Strength of the Study}

This study specifically focused on a group of women using combined oral contraceptive and not on hormonal contraceptives as seen in most related publications.

\section{Limitation of the Study}

The limitation of this study is in the use of Papanicolaou smear test instead of Liquid based cytology which has better sensitivity and specificity. The reason for adopting Pap smear was for its lower cost due to lack of external funding/grants for this study.

\section{Conclusion}

The Prevalence rates of precancerous lesions of the cervix, from this study are similar between the two groups but the use of combined oral contraceptive pills may be associated 
with increased risk of occurrence of HGSIL compared to non-users of COCPs. There may be a need for close followup of users of combined oral contraceptive pills in order to detect those who may develop higher grade precancerous lesions early.

\section{Recommendations}

We suggest further study that comprises multi centered collaboration and large sample size and the use of Liquid based cytology instead of Papanicolaou smear test for cervical cytology test.

\section{Conflicts of Interest}

All the authors do not have any possible conflict of interest.

\section{References}

[1] Norma McFarlane-Anderson. Patience E Bazuaye, Maria D Jackson, Monica Smikle and Horace M Fletcher. Cervical dysplasia and cancer and the use of hormonal contraceptives in Jamaican women. BMC Women Health 2008; 8-9.

[2] Onah H.E. Family Planning. In: Ikpeze O(Ed) Fundamentals of Obstetrics and Gynaecology. $1^{\text {st }}$ Edition. African First Publishers. 2009; 31:305.

[3] Anorlu R.I Tumours of the cervix uteri. In: Akin Agboola(Ed) Textbook of Obstetrics and gynaecology for medical students. $2^{\text {nd }}$ Edition. Heinemann Educational Books Plc.2006; 21:16770 .

[4] Anorlu R.I. Cervical cancer: the Sub-Saharan Perspective. J Reproductive health matters 2008; 16(32):41-9.

[5] IARC Working group on the evaluation on the evaluations of carcinogenic risks to humans on combined oestrogenprogestogen and combined oestrogen-progestogen menopausal therapy. IARC Monogr Eval Carcinog Risk Human Press Lyon (France). 2006; 91:1-528.

[6] Pam VC. Contraception Method Mix and Trend at Jos University Teaching Hospital, Jos J Med 2014; 8(1):5-9.

[7] Cameron ST, Glasier A. Contraception and Sterilization. In: Edmonds DK(Ed). Dewhurst Textbook of Obstetrics and Gynaecology. $8^{\text {th }}$ edition Wiley-Blackwell Publishers.2012; 40:495-504

[8] Vaisy A, Lotfinejad S, Zhian F. Risk of combined oral contraceptive use among Iranian women. Asian Pac J Cancer Prev 2014; 15(14):5517-22.
[9] IA Yakassai, HM Abdullahi, AZ Mohammed and $\mathrm{H}$ Galadanci. Prevalence of cervical dysplasia among women in Kano Municipal, Kano state, Nigeria. J Med Trop 2012; 14(1):64-8.

[10] Ayodele Omotoso, Patience Odusola and Martin Nnoli. Abnormal cervical smears in a tertiary hospital in Nigeria. Sch J App Med Sci 2015; 3(2A):589-94.

[11] Obaseki DE, Nwafor CC. Cervical cancer screening in Benin City, South-South Nigeria. ISOR Journal of dental and Medical sciences (IOSR-JDMS) 2013; 5(1):16-19.

[12] Mohammed Hauwa Inna. Prevalence of Abnormal cervical cytology and knowledge of cervical cancer screening among women attending gynaecologic clinic of General Hospital Minna, Nigeria. Dspace @ my university 2014.

[13] Olusola Aishat Mosuro, Ikeoluwa Ajayi, Akin-Tunde Ademola Odukogbe, Adetunji Oladeni Adeniji, Olayiwola Oluwasola, Effiong Essien Udo Akang et al. Prevalence of cervical dysplasia and associated risk factors among women in a Primary health care Centre clinic in Nigeria. J Basic Clin Reprod Sci 2015; 4(2):70-9.

[14] Duru CB, Oluoha R.U, Uwakwe K.A, Diwe KC, Merenu LA, Iwu CA et al. Pattern of PAP smear test results among Nigerian women attending clinics in a teaching hospital. Int J Curr Microbiol App Sci 2015; 4(4):986-98.

[15] Daru PH, Pam IC, Musa J, Daniyan MG, Silas OI, Adewole IF et al.. Cervical Epithelial changes in Tertiary Hospital in northern Nigeria. Trop J Obstet Gynaecol 2013; 30(1):109-13.

[16] Bukar M, Mayun AA, Audu BA and Inuwa A. Prevalence of preinvasive lesions of the cervix in Maiduguri, North-Eastern Nigeria. J Niger Med Pract 2009; 55(4)52-5.

[17] Solomon Avidime, Saad A Ahmed, Adekunle Oguntayo, Teni $\mathrm{O}$ Abu and James A Ndako. Pattern of Cervical dysplasia among women of reproductive age group in Zaria, Northern Nigeria. J Med Trop 2014; 16:52-5.

[18] Urmila Banik, Pradip Bhattacharjee, Shahab Uddin Ahamad and Zillur Rahman. Pattern of Epithelial cell abnormality in Pap smear: A clinicopathological and demographic correlation. Cyto Journal 2011; 8:8.

[19] Leonard Ogbonna Ajah, Chibuke Ogwuegbu Chigbu, Benjamin Chukwuma Ozumba, Theoplhilus Chimezie Oguanuo and Paul Olisaemeka Ezeonu. Is there any association between hormonal contraceptive and cervical dysplasia in a poor Nigerian setting? Onco Targets Ther 2015; 9: $1887-92$. 